\title{
Specifics of Course Management System Benefits for New University Faculty
}

\author{
Gavin Porter \\ Faculty of Science, the University of Hong Kong \\ 316 Run Run Shaw Building, Pokfulam, Hong Kong \\ Tel: 852-2241-5195Ｅ-mail: porterg@hku.hk
}

Received: July 12, 2011

Accepted: July 15, $2011 \quad$ Published: December 1, 2011

doi:10.5539/hes.v1n2p2

URL: http://dx.doi.org/10.5539/hes.v1n2p2

\begin{abstract}
A comparison of courses that do or do not utilize a Course Management System (CMS) was undertaken from the standpoint of a new faculty member. Seven distinct advantages were found with CMS implementation including initial tutorial group set-ups, email communication, sharing of student generated products, sharing of instructor-generated products, collection of assignments, delivery of graded assignments, and plagiarism checks. CMS training that precedes the start of a course is recommended for new teaching staff, particularly for large courses of greater than 100 students, where CMS implementation has substantial benefits.
\end{abstract}

Keywords: Course Management System, CMS, Teaching, Learning, Technology

\section{Introduction}

Many good studies document various aspects of course management systems (CMSs), including everything from institutional implementation (Morgan, 2003), perceptions and uses (Lonn \& Teasley, 2009), data mining (Romero, Ventura, \& Garcia, 2008), and student experiences (Yuen, Fox, Sun, \& Deng, 2009). Few papers exist that can point directly to how the implementation of a CMS positively impacts an individual faculty member's experience. Such a study would be of great interest to: new faculty members, established faculty members considering the use of a CMS for the first time, University technology staff charged with persuading faculty to adopt CMSs, and also perhaps, the CMS companies themselves.

New faculty members will have varying degrees of experience with technology. Some will be well-versed, others, depending on their discipline, may have minimal experience. Today's new faculty hires may occupy a unique niche in terms of technological background -- they began their college studies at the beginning of the internet age, so they are, hopefully, technologically savvy. However, CMSs were not widespread when they were in the undergraduate stage of their education, when these systems are most commonly implemented. New staff with minimal CMS experiences will have many questions: What are the capabilities of a CMS? Will the time invested in learning the program pay off later? Will the CMS enable better communication between the students and the instructor? What kind of benefits will this communication have?

Immediate, first person accounts of CMS usage by new faculty are not readily apparent in the literature, although some studies have included commentary on faculty's initial experiences in online teaching via interviews (Asbell-Clarke, 2007; Conrad, 2004; Harrington, 2006). These studies reflected on the broader experience of an online course (Asbell-Clarke, 2007), and how faculty use the CMS (Harrington, 2006). Often, instructor's reflections on their performances centered mostly on a role in content delivery (Conrad, 2004).

This study is a first-person experiential account of a new faculty member on the teaching of courses of approximately 100 students with and without the use of a CMS (Web CT). Through teaching in courses that did or did not utilize a CMS, seven pedagogical issues displayed clear contrasts to the author. These issues are discussed in detail, with a point by point comparison of the two conditions, along with data indicating improvement of student satisfaction via the use of a CMS group manager function, and CMS email platform usage vis-à-vis conventional email.

\section{Results}

\subsection{Tutorial Group Set-ups}

When implementing a CMS, numerous advantages in the delivery of a course became apparent (see Figure 1 for a point by point comparison of the non-CMS versus CMS courses). Immediately, it became clear that having a CMS 
in place aided in the setting up of tutorial groups for courses. This was a major concern considering the relatively large class size of 100 students, which gets subdivided into groups of 10-12 students. Also, tutorials are a major focus of the new curriculum being put in place at The University of Hong Kong, so their smooth operation is a major concern. In the course without a CMS ("course 1"), students were asked to sign up on a sheet of paper during a lecture period to indicate which tutorial session they would like to attend. This became quite chaotic and time consuming, as there were 100 students clamoring for their preferred time slot. The students did not take into account the stated capacity guidelines for the tutorials, and an overabundance of students signed up for one or two time slots. Reassigning students away from what they had signed up for, due to space constraints, resulted in many student complaints via email, listing conflicts with other classes or university activities as reasons for reassignment. In courses that incorporated a CMS, a group manager platform enabled students to sign up online a first-come first-served basis for their desired tutorial. Also, a hard cap on the number of students per tutorial section could be put in place using the group manager platform. When the session was full, it simply stopped accepting more students. The student would get this information right away, and then select from the remaining time slots. In the non-CMS course, the students had to wait several days for the list to be processed onto an excel sheet, before they received word on whether they had gotten their desired time slot. The transfer of student names from sheets of paper to an excel sheet for tutorial groups, followed by dissemination via email to all the students in the class, was also time consuming. These steps were completely bypassed through the use of the CMS group manager platform. There were still conflicts in the CMS courses ("courses 2 and 3"), but students raised considerably fewer objections in comparison to the non-CMS course (Figure 2).

\subsection{Email Communication during the Course}

The next apparent difference, which actually stemmed from the tutorial group set-ups, was the use of the group manager email function. This feature was used extensively to send out group-specific information (i.e. asking a question to focus discussion within a group for an upcoming tutorial, reminding students to bring their laptops to a particular session, scheduling changes). Since the tutorials were shared among two instructors, one could quite easily make comments pertinent to their own tutorial sections. Overall, communication was facilitated in the CMS courses, as there was a relative ease in generating class-wide and group specific emails. With the non-CMS course, the instructor was copying and pasting individual student email addresses from an excel roster in order to generate a class-wide email, which is much more tedious by comparison. Communication on an individual tutorial section basis was never undertaken in the non-CMS course.

Given the option of contacting the instructor via conventional email or using the CMS email platform, the students were split roughly in half for their preference. In one CMS course ("course 2"), the students had a slight preference for using a conventional email platform to contact the instructor (Figure 3a). In the other CMS course ("course 3") students had a slight preference for the CMS email interface over conventional email for contacting the instructor (Figure 3b). Taking into account the total number of student to instructor emails in the two CMS courses, the CMS email platform was slightly preferred (Figure 3c). When students are on the CMS course page to look at an assignment or lecture material, it is likely convenient for them to send a message via the CMS email platform to the instructor with any questions that arise. This kind of analysis could not be undertaken for the non-CMS course, as the students only had the one option of conventional email. With the way that Web CT is configured at HKU, even though messages generated through the CMS email platform end up in a conventional email inbox, there is not a way to reply to those messages directly with conventional email. The instructor must log into Web CT to respond to those messages generated via the Web CT email platform. This has been deemed inconvenient by several faculty members.

\subsection{Instructor-shared Products}

No rubrics were made explicit for the non-CMS course. This led to some major discomfort on the part of the students (and the instructor) when the instructor's assessment did not correspond with the student's perceived effort level. The rubric could have been handed out in a class period in the non-CMS course, and thus a CMS is not essential for this kind of dissemination, however in the CMS courses, the rubrics were accessed via the CMS by the students multiple times (course 2 essay rubric $=194$ times, course 2 poster rubric $=137$, course 3 essay rubric $=143$, course 3 oral presentation rubric $=60$ ), strongly suggesting that a central depository for the rubrics was well-utilized. Also, there was a difference in the number of students who had a major disagreement with grades among the courses. In course 1 (no CMS), 7 students had major disagreements over an assignment grade, whereas in the two CMS courses combined, only 3 students approached with major disagreements over an individual assignment grade. This suggests that the presence of an online rubric helps to reconcile instructor and student perceptions on assessments. 


\subsection{Student Shared Products}

The CMS also allowed for exchange of information between students. There were discussion boards utilized by students for group collaboration on assignments. Students could post rough copies of presentations for group consumption, and then make appropriate suggestions to improve the work prior to final submission for grading. The students in one of the CMS courses (course 2) had the opportunity to create rubrics for peer-to-peer evaluation of a poster presentation assignment. Some of these were completed by students and put onto the CMS before the presentation, so that students could have an idea of what their peer's criteria for assessment would be.

\subsection{Assignment Collection}

The use of an assignment drop box function on the CMS permitted acquisition of electronic (soft) copies of assignments. This is easier for the students as they can submit an assignment from anywhere they have internet and computer access. All of the major assignments in the non-CMS course were collected via hard copies.

\subsection{Delivery of Assignment Feedback}

Soft copy feedback can be given to students using track changes on their essays, and was indeed done for a proportion of the students in one of the CMS courses. By the end of the semester, an instructor had found several advantages in doing all of the assessment and feedback via soft copy means (i.e. legibility of typed comments is quite clear, easier to insert new text/rewrite thesis statements, making rubric can be pasted in). Also, the collection rate for hard copy assignments was rather low at times (less than 50\% for an end of semester essay). As a lot of effort is put in on the part of the instructor to give detailed feedback on the assignments, it seemed a shame that students did not put in the effort to collect it. Soft copy feedback, delivered via the CMS can potentially reach all of the students, and the detailed comments are just a few mouse clicks away. Whether they choose to read and internalize the feedback is another issue altogether and beyond the scope of a discussion on CMS usage. A recent study found that $87 \%$ of students and $89 \%$ of teachers deemed the turning in of assignments online as either valuable or very valuable (Lonn \& Teasley, 2009). Likewise, there were also very positive opinions expressed about the return of assignments online with $85 \%$ of students and the same percentage of teachers deeming it to be either valuable or very valuable (Lonn \& Teasley, 2009).

\subsection{Plagiarism Checks}

In the non-CMS course, plagiarism checks were accomplished by typing in suspicious passages from hard copy essays into an online search engine to determine if they were copied from an online source. In the CMS course, all of the electronic copies of assignments from the Web CT dropbox were scanned via the Turnitin program. The Turnitin approach seems to be preferable because it is applied uniformly, and is less time consuming for the instructor than determining whether plagiarism has occurred via comparison with various online sources. Furthermore, the Turnitin scan will also compare the student's work to text sources (printed books and articles, not just those online), and also to work that has been submitted by current and previous year's students. In the case of the current year's students, this can rule out collusion. This may be difficult to rule out on hard copies if the similar essays are separated by a large number of others in the grading process. To our dismay, we found several cases of students that had plagiarized from essays that were submitted in a previous year's course of a similar topic. These would have been missed with an online search as they would not have been publicly available on the internet. Each case with a high degree of similarity found via Turnitin was double checked by multiple instructors to examine the sources and severity of the plagiarism, so there was certainly a human element in the process as well. For better or for worse, the internet is being used quite extensively by students now as a research source. The copy and paste function is quite tempting to students, and HKU has the unusual circumstance of many of its students studying in their second language, English, for the first time. The presence of an electronic check for plagiarism is becoming an essential aspect to build into assessments.

\section{Discussion}

In no way is the author suggesting that Web CT is preferable as a CMS over other options (such as Moodle, Sakai, Mahara, etc.). I realize, and have had many colleagues point out, the shortcomings of Web CT - particularly with its email platform and user interface. However, in larger classes, the presence of a CMS, even one with some flaws, has many immediately tangible advantages over no CMS at all, as one can clearly see from the analysis. Also, it is acknowledged that not every aspect detailed in this paper absolutely relies on the presence of a CMS. For example, rubrics could have been handed out in hard copy in class, and students could email electronic copies of assignments to the instructor. However, by acting as a central depository, the CMS greatly facilitates these activities. Web CT does hold importance by virtue of its widespread usage, with implementation at thousands of colleges and universities around the world (Finkelstein, 2003). 
One of the major benefits of a CMS which doesn't directly relate to the teaching process itself is time savings on administrative tasks. Undoubtedly, this time can be re-invested in things which do directly and positively impact teaching and learning such as content development and interaction with students. Instructors, and also students, have cited increased efficiency (saves time) as one of the top two benefits for CMS usage (Lonn \& Teasley, 2009). Improved instructor to student communication is also cited as being important (Lonn \& Teasley, 2009). Both parties save time and communicate better when a CMS is present.

Instructors could benefit from a CMS workshop and help with implementation of a CMS prior to the beginning of the semester. This wouldn't necessarily have to occur in a formal manner, but could occur with co-instructors in the course or fellow faculty members who already have CMS experience. Studies show that CMS training is more effective when it utilizes faculty peers (Morgan, 2003). The author received a 2-hour formal training session from the University's Computer Centre on the basics of Web CT. This was beneficial in that the capabilities of the CMS were clearly laid out, and any trepidation about playing around with the system was removed. Training from a campus learning center was the second most cited reason for adoption of a course CMS, and once a faculty use a CMS, their use of technology tends to grow (Morgan, 2003). Thus, getting new faculty hires some CMS training could be one of the most beneficial things a university technology division could do to increase faculty usage of new teaching technologies. The presence of a course CMS made a substantial positive difference to the author, a new faculty member in the university. Once the new teacher progresses and gains experience with a relatively simple technology like a CMS, the road is paved to embark on greater and more sophisticated technology use in the classroom. In this way, the CMS can be viewed as a "gateway drug" - a beneficial one. However, degree of implementation of CMSs also needs to be monitored, and likely encouraged by university technology staff. Surprisingly, over a third of faculty surveyed admit to implementing only one feature of a CMS (Malikowski, 2008). This study clearly demonstrates the benefits of using multiple aspects of a CMS.

\section{Conclusion}

In conclusion, the implementation of a CMS led to clear benefits in saving instructor time, enabling of tutorial group set-up, alleviating student concerns/objections, facilitating both student to student and instructor to student communication, collection and delivery of feedback on assignments, and plagiarism checks. In large sized classes, it is highly recommended to new faculty and teaching staff that a CMS be implemented.

\section{References}

Asbell-Clarke, J., \& Rowe, Elizabeth. (2007). Learning Science Online: A Descriptive Study of Online Science Courses for Teachers. Journal of Asynchronous Learning Networks, 11(3), 95-121. [Online] Available: http://sloanconsortium.org/sites/default/files/v11n3_6asbellclarkerowe_0.pdf

Conrad, D. (2004). University Instructors' Reflections on their First Online Teaching Experiences. Journal of Asynchronous Learning Networks, 8(2), 31-44. [Online] Available: http://sloanconsortium.org/sites/default/files/v8n2_conrad_1.pdf

Finkelstein, J., \& P., M. (2003). The evolving role of Course Management System Providers in the Transformation of Education: An interview with Blackboard's Matthew Pittinsky. The Technology Source Archives, January/February 2003. [Online] Available: http://technologysource.org/article/evolving_role_of_course_management_system_providers_in_the_transformation _of_education/

Harrington, T., Staffo, M., \& Wright, VH. (2006). Faculty Uses and Attitudes toward a Course Management System in Improving Instruction. Journal of Interactive Online Learning, 5(2), 178-190. [Online] Available: http://www.ncolr.org/jiol/issues/pdf/5.2.4.pdf

Lonn, S., \& Teasley, S. D. (2009). Saving Time or Innovating Practice: Investigating Perceptions and Uses of Learning Management Systems. [Reports - Evaluative]. Computers \& Education, 53(3), 686-694. http://dx.doi.org/10.1016/j.compedu.2009.04.008

Malikowski, S. R. (2008). Factors relted to breadth of use in course management systems. Internet \& Higher Education, 11(2), 6. http://dx.doi.org/10.1016/j.iheduc.2008.03.003

Morgan, G. (2003). Faculty use of Course Management Systems, Research Study from the EDUCAUSE Centre for Applied Research (ECAR) (Vol. 2): EDUCAUSE. [Online] Available: http://net.educause.edu/ir/library/pdf/ers0302/rs/ers0302w.pdf

Romero, C., Ventura, S., \& Garcia, E. (2008). Data mining in course management systems: Moodle case study and tutorial. Computers \& Education, 51(1), 17. http://dx.doi.org/10.1016/j.compedu.2007.05.016 
Yuen, A., Fox, R., Sun, A., \& Deng, L. (2009). Course Management Systems in Higher Education: Understanding Student Experiences. Interactive Technology and Smart Education, 6(3), 189-205. http://dx.doi.org/10.1108/17415650911005393

\section{Notes}

Portions of this work were presented orally at the Centre for Information Technology Research Symposium held at the University of Hong Kong, June 30, 2011.

\begin{tabular}{|c|c|c|}
\hline & Lack of CMS ("course 1") & CMS (Web CT) ("course 2" and "course 3") \\
\hline $\begin{array}{l}\text { Initial tutorial group } \\
\text { set-ups }\end{array}$ & $\begin{array}{l}\text { Chaotic sign ups during lecture period (100 } \\
\text { students signing a sheet of paper) } \\
\text { Time-consuming and arduous (transfer of } \\
\text { student names to excel sheets for time slotting } \\
\text { and record keeping purposes) } \\
\text { Large student demand for several time slots - } \\
\text { caved in to demand } \\
\text { Large number of complaints regarding conflicts }\end{array}$ & $\begin{array}{l}\text { Students self-assigned to various tutorial } \\
\text { sections via the CMS } \\
\text { Relatively easy to set up groups via the CMS - } \\
\text { multiple options including self-assignment } \\
\text { Group numbers capped by instructors } \\
\text { Less complaints regarding conflicts }\end{array}$ \\
\hline $\begin{array}{l}\text { Email communication } \\
\text { during the course }\end{array}$ & $\begin{array}{l}\text { Non-existent on an individual tutorial group } \\
\text { level } \\
\text { Time consuming on the class-wide level } \\
\text { (cutting and pasting email addresses from a } \\
\text { class roster into an email message) } \\
\text { Students used conventional email (@hku } \\
\text { addresses) only, for communication with } \\
\text { instructor }\end{array}$ & $\begin{array}{l}\text { Made frequent use of group manager email } \\
\text { function for reminders in specific tutorials } \\
\text { "All students" email function was relatively } \\
\text { easy to use. } \\
\text { Students had the option of CMS email platform } \\
\text { or conventional email (@hku addresses) for } \\
\text { communication with instructor }\end{array}$ \\
\hline $\begin{array}{l}\text { Shared } \\
\text { student-products from } \\
\text { tutorials }\end{array}$ & none & $\begin{array}{l}\text { Student-generated rubrics for peer to peer } \\
\text { evaluation were posted on the CMS }\end{array}$ \\
\hline $\begin{array}{l}\text { Instructor-shared } \\
\text { rubrics which preceded } \\
\text { assessment }\end{array}$ & $\begin{array}{l}\text { None; this led to some discomfort on the part } \\
\text { of students (and instructor) when there was a } \\
\text { discrepancy regarding the expectations for an } \\
\text { assessment } \\
\text { Major disagreement with grade } \\
\text { Course } 1=7 \text { students }\end{array}$ & $\begin{array}{l}\text { Essay writing rubric, poster presentation rubric, } \\
\text { oral presentation rubrics all posted to the CMS } \\
\text { prior to assignment submission } \\
\text { Major disagreement with grade } \\
\text { Course } 2=0 \text { students } \\
\text { Course } 3=3 \text { students } \\
\text { \# of times students accessed rubrics via the } \\
\text { CMS: } \\
\text { Course } 2=194 \text { (essay), } 137 \text { (poster } \\
\text { presentation) } \\
\text { Course } 3=143 \text { (essay), } 60 \text { (oral presentation) }\end{array}$ \\
\hline $\begin{array}{l}\text { Assignments handed in } \\
\text { via }\end{array}$ & Hard Copy & Soft copy via CMS assignment drop box \\
\hline Soft-copy feedback & None given & Given to some course 2 students on essays \\
\hline Plagiarism check & $\begin{array}{l}\text { Accomplished by instructor typing suspicious } \\
\text { passages into Google from hard copy essays } \\
\text { Plagiarism cases identified: } \\
\text { Course } 1=3\end{array}$ & $\begin{array}{l}\text { Turnitin applied to Web CT dropbox; uniform } \\
\text { application to all student essays } \\
\text { Plagiarism cases identified: } \\
\text { Course } 2=7 \\
\text { Course } 3=3\end{array}$ \\
\hline
\end{tabular}

Figure 1. Factor by factor breakdowns for differences between non-CMS and CMS courses 


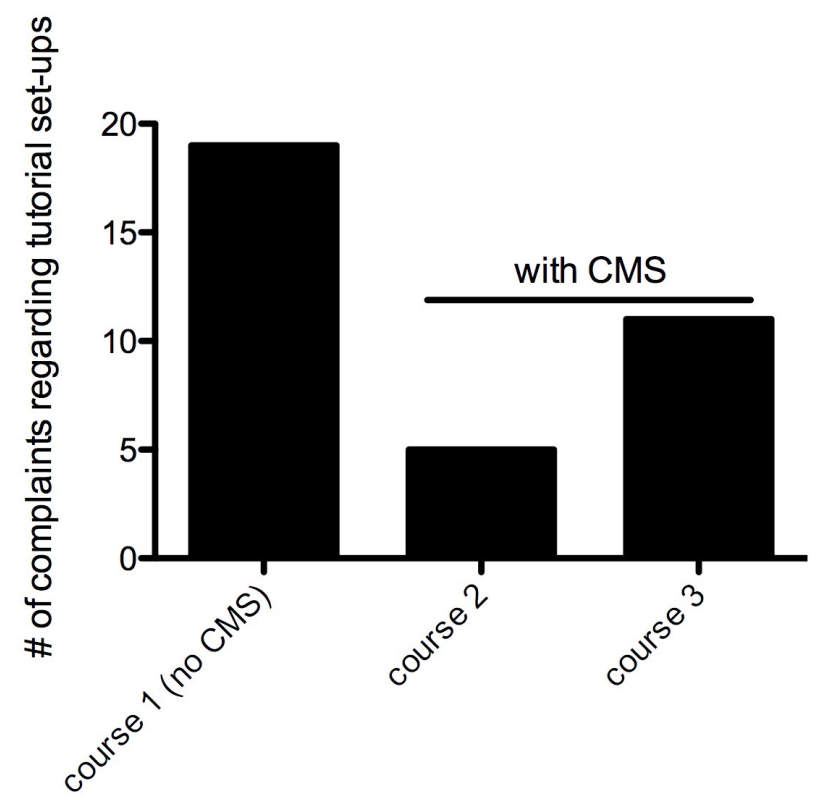

Figure 2. CMS group manager platform decreased student objections to tutorial timeslot

Students made a total of 19 complaints in the non-CMS course in regards to tutorial timeslots, whereas fewer complaints were seen in both of the CMS courses combined $(5+11)$.

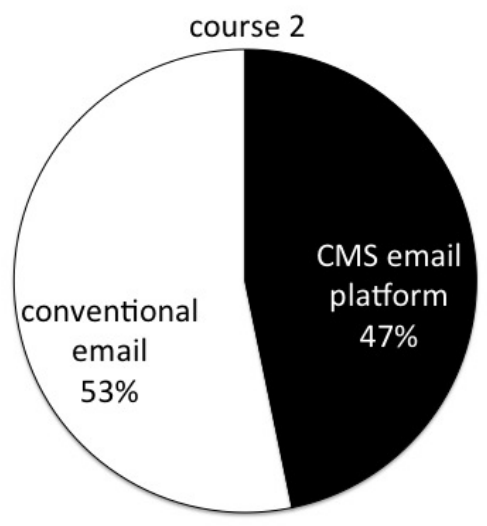

a

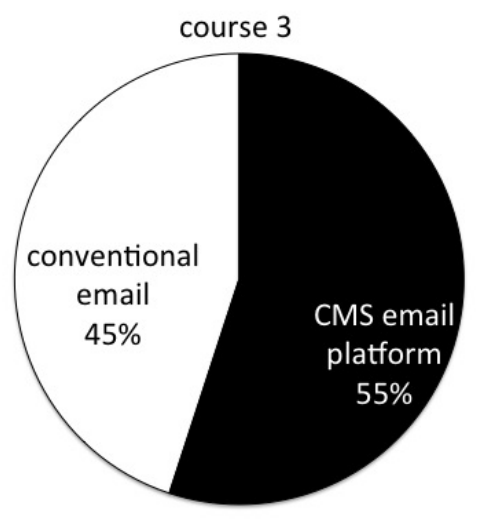

b

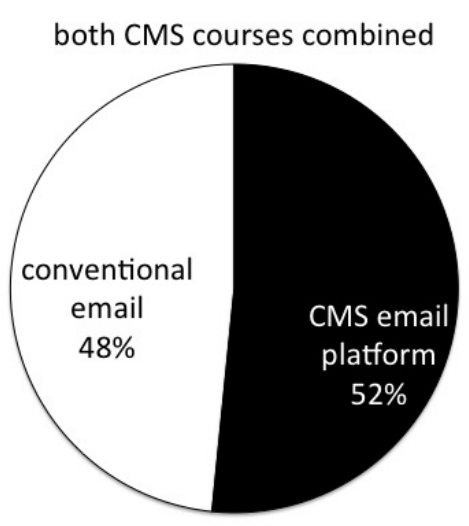

C

Figure 3. Email traffic in courses utilizing a CMS

Student to instructor emails, both through conventional email and CMS email platforms, were tallied for the two courses that employed a CMS. The third chart is representative of the total number of emails from both of the CMS courses combined. In the combined case, students have a slight preference for communication with instructor through WebCT email platform. 